\title{
Evaluating a school based childhood obesity intervention for posture and comfort
}

\author{
Mark Benden, Adam Pickens, Eva Shipp, Jase Perry, Drew Schneider
}

Texas A \& M Health Science Center, College Station, USA; dschneider@srph.tamhsc.edu

Received 20 May 2013; revised 21 June 2013; accepted 19 July 2013

Copyright (c) 2013 Mark Benden et al. This is an open access article distributed under the Creative Commons Attribution License, which permits unrestricted use, distribution, and reproduction in any medium, provided the original work is properly cited.

\section{ABSTRACT}

Background: Research shows that students who are more active throughout the day have fewer reports of body part discomfort and greater energy expenditure needed to combat childhood obesity. Many factors may contribute to the overall health of the child, including the postures that are required to complete assigned tasks at their school workstations. Decreasing sedentary behaviors in children through the use of standing desks at school has been shown to increase calorie expenditure and may be a viable approach to the energy imbalance typical of modern children. The objective of this research was to quantify and analyze sub-optimal postures and self-reported discomfort of students during the use of traditional seated and standbiased desks to determine whether any unintended consequences of the intervention were present. Methods: A postural analysis based on the Portable Ergonomic Observation (PEO) method was used to assess the posture of 42 elementary school students as they worked at their assigned workstation (either standing or seated). Two classrooms contained stand-biased workstations (15 students) and two classrooms had traditional seated workstations (27 students). Each student was assessed three times at $\mathbf{1 0}$ minutes, for a total of $\mathbf{3 0}$ minutes of observations each. The percent of time spent in preferred versus non-preferred postures was then computed. Student body part discomfort surveys were used to assess the discomfort of students between the two groups. The relationship between type of workstation and percent time in non-preferred postures and body discomfort was examined using Wilcoxon ranksum tests and Fisher's exact tests, respectively. The significance level was $p \leq 0.05$ for all of the two-sided tests. Results: No significant difference was found between the two groups and time spent in non-preferred postures and body discomfort, children using stand-biased workstations reported less discomfort overall. Standbiased desks presented no additional ergonomic issues, while providing increased caloric expenditure. Conclusions: A study containing a larger sample and older children that includes postural observation throughout the school day is needed for future research.

Keywords: Childhood Obesity; Elementary Health; Ergonomics; Stand-Biased; Posture

\section{INTRODUCTION}

Obesity is an increasing threat to children in economically developed countries. The obesity epidemic can cause a plethora of health problems in children, including: hyperinsulinemia, glucose intolerance, an increased risk of Type II diabetes, hypertension, and sleep apnea [1]. Overweight or obese children may also suffer from social and psychological issues due to teasing and poor body image, and these issues can carry into adulthood [1,2]. Childhood obesity is doubly dangerous because of the long lasting social and psychological issues and health problems that persist and often worsen during adulthood [2].

Research by the US Department of Health and Human Services, shows that low levels of activity increase the risk of obesity in adults [3]. It is reasonable to assume that the environmental factors that affect adults also impact children. Studies have also found a relationship between the home and neighborhood environments of children and their physical activity [4,5]. Office work is now prevalent within economically developed societies, causing many people to be tethered to a workstation from elementary school to retirement. 
Children utilize workstations in different ways and it is known that a person's posture plays an integral role in overall body comfort. A significant amount of research has been devoted to the study of office ergonomics for adults, but little has been done to study the effects of the school environment. In essence, the school classroom environment is the "work" environment for children [6].

Children assume different postures at workstations than adults. However, it is difficult to assess how posture may negatively affect a child in the future, because they continually change as they grow and develop. There is evidence that the onset of lower back pain in childhood is a risk factor for lower back pain as an adult [7-10]. Research has also shown that static sitting with poor posture is common and modifications may be necessary to prevent future back pain [11].

A study by Damkot, et al. indicates that bending forward movements of the spine increase the risk of lower back pain [12]. Other studies illustrate that energy expenditure increases as much as $25 \%$ when people are standing, as opposed to sitting [13,14]. A pilot study from research at the Texas A \& M Health Science Center's School of Rural Public Health confirms that standing, rather than sitting, increases energy expenditure [15]. Elementary school children spend a majority of their day at a school workstation. These seated workstations provide children with little opportunity to move and expend calories. As childhood obesity levels continue to rise at alarming rates, interventions, including stand-biased workstations, need to be adopted in order to facilitate increased caloric expenditure throughout the school day [16].

Pilot studies show that children standing at stand-biased workstations have greater energy expenditure compared to their sitting counterparts [15]. Although the effects of excessive sitting in children is not known, research shows that prolonged sitting in adults can have dire consequences and may lead to a shorter lifespan [17, 18]. These same studies state that humans have evolved to become bipedal and ambulatory over the course of millions of years and are not meant to sit all day [17-19]. Other research strongly suggests that sitting habits differ greatly in traditional seated schools and institutions where movement is encouraged through environmental intervention [20].

The purpose of this study was to identify how children in a second grade elementary school use their workstations and how their workstations impact posture and overall comfort.

\section{METHODS}

\subsection{Subjects}

A total of 42-second grade students, 22 males and 20 females, were recruited from four randomly selected classrooms at College Hills Elementary School in College Station, TX. Approval for the study was gained through TAMU-IRB and the College Station Independent School District (CSISD). Consent forms were sent out to parents for approval to enroll their children in the study.

The study consisted of two standing treatment classrooms (Classrooms $\mathrm{A}$ and $\mathrm{B}$ ) and two seated control classrooms (Classrooms C and D). Classrooms A, B, C, and $\mathrm{D}$ each had $12,14,18$, and 16 total students, respectively and 5, 10, 16, and 11 participants, respectively. The number of participants was limited by the number of consent forms returned as well as the assent of the participants. Study participant age ranged from 7 - 9 years, with $53 \%$ of the participants being age 7 . Only 2 participants ( 5\%) were 9 years old.

\subsection{Instruments}

The study compared traditional seated workstations and stand-biased workstations. The traditional seated workstations were Scholar Craft Products, Model 2200 FBBK Series, manufactured in Birmingham, AL. These desks had limited adjustability, but the school never made adjustments. Facilities personnel set all workstations at the same height $(60 \mathrm{~cm})$ during the initial installation. The chairs for the seated workstations were the 9000 Classic Series, manufactured by Virco, of Torrance, CA.

The stand-biased workstations were manufactured by Artco-Bell Inc. in Temple, TX and were part of the Archetype Series. The workstations featured a footrest and stool, allowing the students to sit when desired. All stand-biased workstations were adjusted to each student at, or slightly below, the standing elbow height, prior to beginning the study to assure proper use and fit of the equipment.

A body part discomfort survey developed by the research team was distributed to assess self-reported levels of discomfort caused by the workstations. The research team used an age appropriate, body part discomfort survey as part of a first year pilot study [15,24].

A postural analysis technique, based on the PEO, was developed for this study. The analysis method was built from previous pilot studies, at the Texas A \& M HSC$\mathrm{SRPH}$, along with previous ergonomic research to incorporate body position and degrees of movement [11,20-23].

The postural analysis forms were used to assess the various postures displayed by students as they completed assignments. The researcher only collected data as students performed individual assignments at their workstations. It was decided to collect data in this manner to minimize teacher effects, since it was observed that each teacher had a unique teaching style potentially influencing how the workstations were used. 


\section{PROCEDURE}

Body part discomfort surveys were distributed to all students 12 days prior to postural analysis to assess any self-reported discomfort caused by their workstations. The teachers explained that the discomfort they reported was solely caused by the workstations and not other factors, such as playground accidents or illnesses.

Using the SRPH-developed postural observation technique, student postures were observed. The research team recorded student postures in both the control and treatment groups. They first positioned themselves to look at the sagittal plane of an individual participant. The researcher then started a stopwatch and used the Postural Observation Sheet (Figure 1) to identify the posture that most closely resembled the position of the child. A postural observation was noted on the Postural Data Collection Sheet after each minute, for 10 minutes. This was done three times for each student, for a total of $30 \mathrm{~min}-$ utes of observation for each participant. After the researcher had performed a 10-minute postural analysis on all of the students in one class, the researcher moved to the next class and performed the same 10-minute analysis on those students.

Data were also recorded with respect to if the student's neck was in flexion or extension and whether or not they were resting their elbows/forearms on the workstation. It was also noted in the "Comments" section if there were any noticeable contact stresses from the furniture, whether the student's arms and legs were crossed, and any unscripted postures not intended for the workstation. Unscripted postures, for the purpose of this study, were any postures assumed by participants, which would not be considered appropriate for the design of the workstation. Common unscripted postures included students leaning back in chairs on two legs, sitting on their legs while in their chair or stool, sitting sideways, etc.

It should be noted that only postures observed at the start of each minute were recorded. It was observed that postures did change throughout the minute, but marking the posture at the start of each minute ensured consistency throughout the study. If a student was absent from their workstation at the beginning of a minute in their observation session, the researcher marked an " $X$ " and treated it as a missing data point for analysis. Similarly, if the student moved during a minute of data collection, the researcher noted it in the "Comments" section of the Data Collection sheet, but the movement did not influence statistical analysis. The researcher collected between 20 and 30 units of observation within the 30 minute time period. Only three students did not have between 20 to 30 units of observation time.

\section{DATA ANALYSIS}

Analysis for this study addressed two primary null hypotheses.

- The discomfort level of the children using the standbiased workstations is equal to the children at seated workstations.

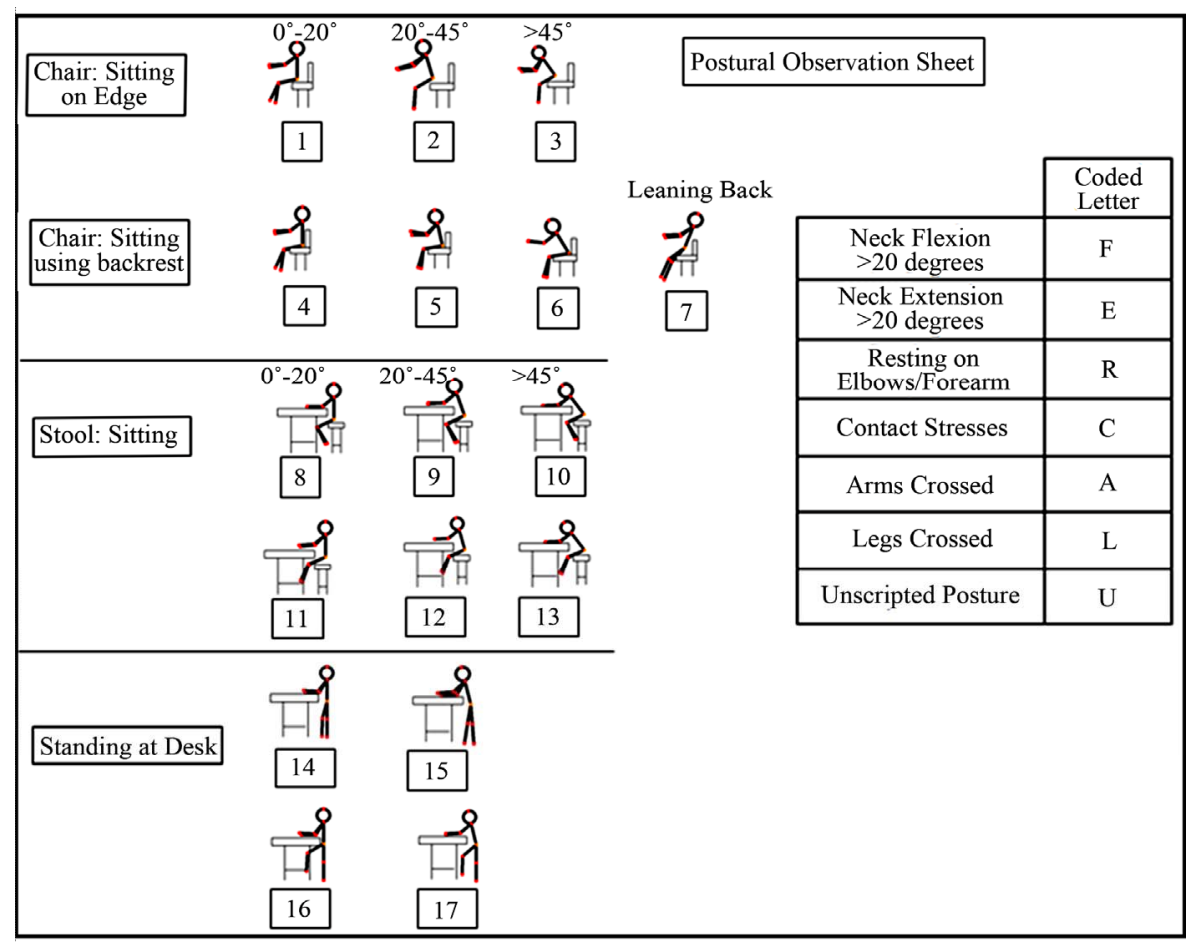

Figure 1. Postural observation sheet. 
- The proportion of time spent in non-preferred postures, for students using stand-biased workstations, is equal to the students in seated workstations.

The independent variable was the workstation type (stand-biased and seated). Dependent variables included self-reported discomfort level from the Student Body Part Discomfort Survey and observed percent time in non-preferred postures.

Descriptive statistics were used to describe all variables of interest. Categorical variables were described using proportions, while continuous variables were described using ranges, means, and standard deviations. The significance level for all statistical tests used to examine the two main objectives was $p<0.05$. All statistical tests were two-sided.

Self-reported discomfort levels were quantified for each major body part region and ranged from 1-5. This was then condensed to a range from 1-3 during analysis based on the distribution of the data. The three categories for discomfort were considered good, neutral, and poor from 1-3, respectively. The relationship between the type of workstation and self-reported body part discomfort were quantified using the chi-square test and Fisher's exact test due to the occurrence of a small number of endorsements for some of the categories of discomfort.

Preferred and non-preferred postures were determined by the research team, which consisted of two ergonomists, one of who is a Certified Professional Ergonomist, and the other, has a research history in biomechanics. Circles in Figure 2 identify these postures. The propor- tion of time spent in various postures was calculated as the minutes spent in a particular posture divided by the total minutes observed at the workstation.

The distribution of the posture data was observed. There was evidence that the data were not normally distributed. Consequently, a Wilcoxon rank sum test was used to examine the relationship between type of workstation and percent time in non-preferred postures.

Potential confounders for this study included gender, height, weight, and teacher. The relationship between these potential confounders and type of workstation was assessed using the same two-sided tests and significance level $(p<0.05)$ as the main set of analyses.

\section{RESULTS}

Participants ranged from 7 - 9 years of age. The distribution of height and weight were similar in both the control and treatment classrooms. One student had missing values for their height, weight, and age. This individual was still included in the study, since data were collected for posture and body part discomfort. The distribution of height and weight for the sitting and standing students can be seen in Table 1. There was no significant difference between the seated and standing groups with respect to the key confounders of interest. Although "teacher" could also be a potential confounder, this variable was highly correlated with workstation type. Consequently, the potential confounding effect of teacher could not be evaluated. On average, students stood $12.3 \%$ of the time with a range of $0 \%$ to $27 \%$, while

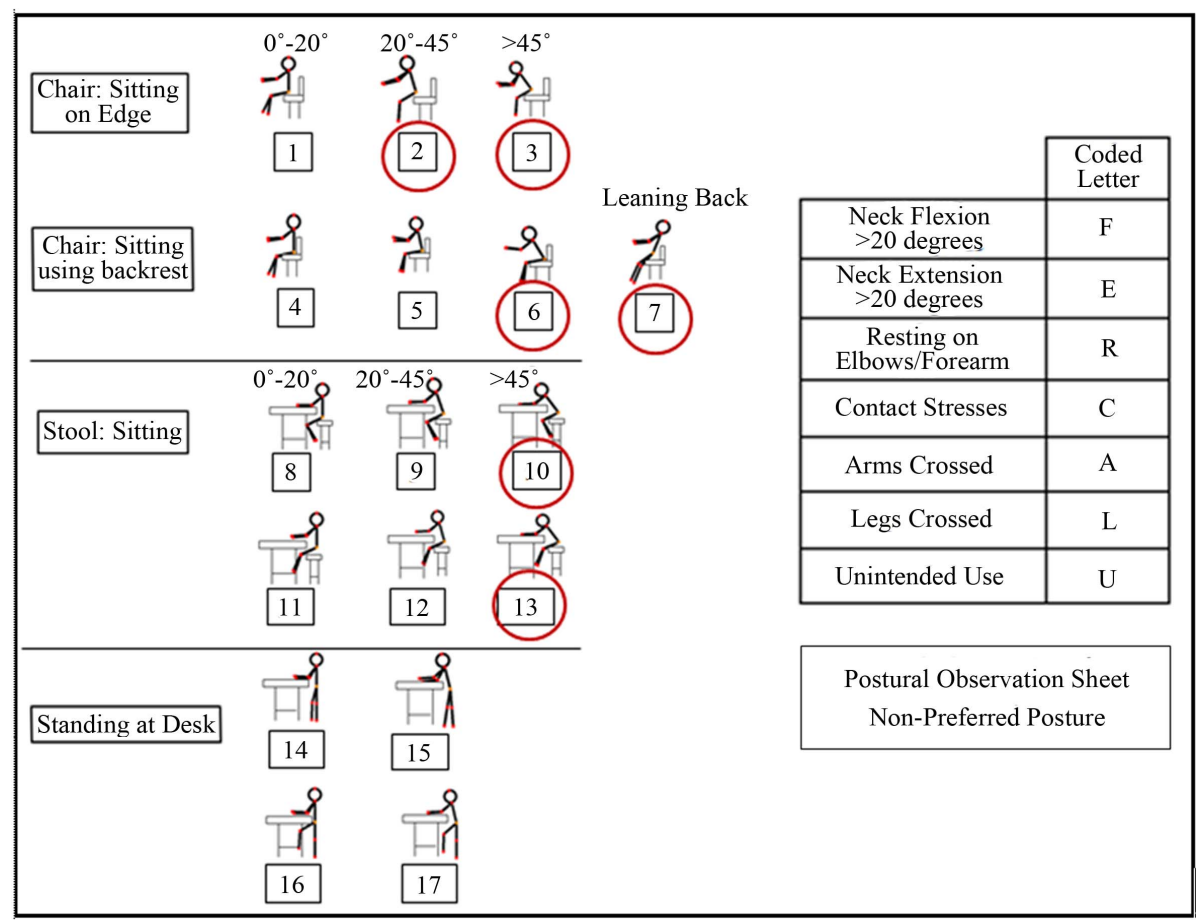

Figure 2. Circled non-preferred posture. 
Table 1. Descriptive statistics for sitting and standing students.

\begin{tabular}{ccccccccc}
\hline & \multicolumn{3}{c}{$\begin{array}{c}\text { Height (Centimeters) } \\
\text { Wilcoxon Rank-Sum Test } \\
z=0.48 p=0.63\end{array}$} & \multicolumn{2}{c}{$\begin{array}{c}\text { Weight (Kilograms) } \\
\text { Wilcoxon Rank-Sum Test } \\
z=0.70 p=0.48\end{array}$} & \multicolumn{2}{c}{$\begin{array}{c}\text { Gender } \\
\text { Fisher's Exact 0.53 }\end{array}$} \\
& Mean & SD & Range & Mean & SD & Range & Male (\%) & Female (\%) \\
Sitting Students $n=27$ & 130.7 & 6.3 & $113.8-139.8$ & 30.4 & 9.4 & $19.3-59.1$ & $13(0.48)$ & $14(0.52)$ \\
Standing Students $n=15$ & 132.1 & 6.0 & $122.9-143.6$ & 30.5 & 4.7 & $24.1-37.8$ & $9(0.60)$ & $6(0.40)$ \\
Combined $n=42$ & 131.2 & 6.2 & $113.8-143.6$ & 30.5 & 8.0 & $19.3-59.1$ & & \\
\hline
\end{tabular}

working on an assignment at their workstation. There were outliers who stood almost $40 \%$ and more than 50\%, respectively.

Overall, the body part discomfort surveys found that students in the standing classrooms reported greater comfort for their neck, arms, and legs, while the sitting classes reported greater comfort for the lower back, wrists and hands, and ankles and feet. The sitting classrooms also reported greater discomfort in all areas of the body than the standing students, as seen in the combined data in Figure 3. A larger proportion of the standing students reported a neutral comfort level for all body parts, except the arms.

Analysis of the body position/posture data indicated greater neck flexion and extension in the treatment group. However there were only 15 , out of 42 participants that illustrated any extension greater than 20 degrees. All participants exhibited flexion of the neck, greater than 20 degrees at some point during their observation period. This was likely due to data being collected only when students were working on handwritten assignments.

A greater proportion of the standing students portrayed more time in preferred postures and less time in nonpreferred postures. Using a Wilcoxon rank-sum test, the two treatment groups were compared with respect to the percent time observed in non-preferred postures. There was no statistically significant difference $(p>0.05)$ based on this test.

\section{DISCUSION}

The purpose of this pilot study was to identify the discomfort level of children using stand-biased workstations compared to that of children at seated workstations. Researchers also sought to identify non-preferred postures for students using stand-biased workstations compared to students at seated workstations. The data analyzed in this study found no statistically significant difference between the stand-biased and seated workstations $(p>0.05)$ with respect to either time spent in nonpreferred postures or body discomfort. There were, however, many interesting observations that are informative for future research studies.

Research findings showed that approximately 75\% of

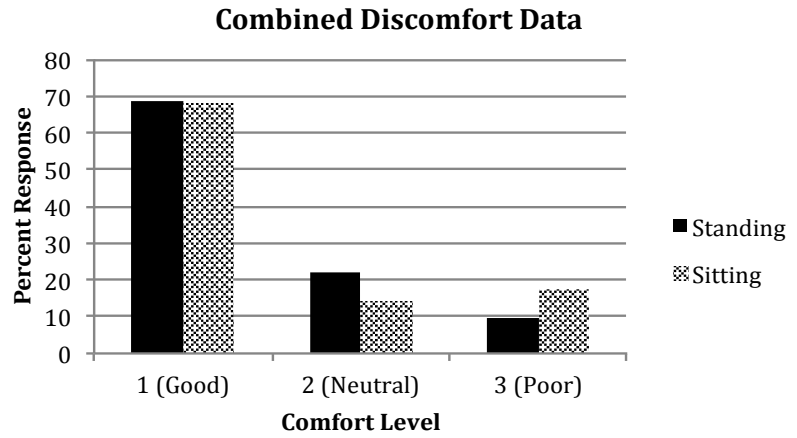

Figure 3. Discomfort data.

students in seated workstations could not touch the floor with their feet when seated. This illustrates the importance of workstation design for elementary schools, as the anthropometry of students between grade levels can vary substantially. The school in this study used the same size $41 \mathrm{~cm}$ high seat for kindergarten through fourth grade. This eliminates all but the tallest fourth graders from being able to sit properly in the seats. The standbiased workstations proved to be more effective in fitting each individual student due to the flexibility of standing and the large adjustment ranges of the stool and workstation.

One of the greatest advantages of this study over previous pilot studies was interacting with the teachers and allowing them to communicate with students about the Body Part Discomfort Survey. The teachers illustrated the importance of reporting accurate discomfort with respect to the workstations.

\section{LIMITATIONS}

Sample size was the major limitation in this study. Although appropriate for a pilot study, the small sample size may have limited the ability to detect a statistically significant association due to low power. Furthermore, participants were only localized to one school. More participants, from multiple schools, will be needed in future studies to extrapolate findings beyond a single school. For example, it is also important to note that students were the product of an urban environment and overall discomfort or the use of workstations may be different in 
a rural setting.

Prior to beginning the study, it was apparent that there was a potential for a teacher effect. Teachers had their own, unique teaching style that made it difficult to assess the role that posture played throughout the school day. Some teachers chose to lecture while the students were at their workstations. Other teachers had their students participated from the floor, or from other areas within the classroom, limiting their time at their workstations. This is why it was decided to collect data when students were working by themselves at their workstations. The potential exists for significantly more time at the workstation in higher grades, as many teachers place students on the floor to teach in second-grade classrooms.

Another factor that may have influenced how participants used their workstations was the presence of the researcher. Although students were never told when they were going to be observed, the presence of the researcher may have altered student behavior and the classroom dynamic.

\section{CONCLUSION}

As a pilot study, several lessons were learned for future researches. While there was no statistically signifycant difference in either posture or discomfort, standing students reported an overall lower discomfort than their seated peers. The teaching style of the classrooms, which is more variable in early grades, contributed to an overall minimization of time at the workstations. Future studies should include older student populations, where workstations are the primary site for lecture and individual work among the students.

\section{IMPLICATIONS FOR OBESITY}

The results of this study and the intervention of a stand-biased workstation in classrooms have the potential to profoundly impact the health of students by promoting more movement throughout the school day. Students will burn more calories, which may have a positive impact on their weight. Additionally, the stand-biased desk has the potential to reduce long-term musculoskeletal disorders of the low back due to improper seated postures. The intervention of a stand-biased desk could improve the health of children as they mature into adults and enter the workforce.

Previous studies show the more immediate benefits to these types of interventions. Students who are more active report better grades and attention while in class [20,25]. Additionally, the calorie expenditure goals noted in the recent article of Wang, et al. needed to achieve Healthy People Goals by 2020 are similar to those reported in interventions of stand biased desks in elementary students. Additionally, overweight and obese stu- dents have a greater benefit in total calorie expenditure as both a total and a percentage increase [22-26].

There are a number of obstacles in implementing a standing workstation. School budget cuts are becoming more prevalent, and many districts have a difficult time replacing traditional seated workstation with stand-biased workstations because of cost. The transition to stand biased desks needs to be slow and progressive, starting with new schools, or converting only a few classrooms at a time in existing schools, as seen in this study. Schools may decide that other interventions may be more appropriate and feasible for their students. However, when new schools are being built and new equipment is being purchased, it is important to keep in mind what products would encourage healthy movement of the children.

\section{REFERENCES}

[1] Lobstein, T., Baur, L. and Uauy, R. (2004) Obesity in children and young people: A crisis in public health. Obesity reviews, 5, 4. doi:10.1111/j.1467-789X.2004.00133.x

[2] Dean, H. and Flett, B. (2002) Natural history of type 2 diabetes diagnosed in childhood: Long term follow-up in young adult years. Diabetes, 51, A24-A25.

[3] Manley, A. (1997) Physical activity and health: A report of the surgeon general. Department of Health and Human Services, Washington, September 15, 1997.

[4] Ewing, R. (2005) Building environment to promote health. Journal of Epidemiology \& Community Health, 7, 536-537. doi:10.1136/jech.2004.032367

[5] Sirard, J., Laska, M., Patnode, C., Farbakhsh, K., Lytle, L. (2010) Adolescent physical activity and screen time: Associations with the physical home environment. The International Journal of Behavioral Nutrition and Physical Activity, 7, 82. doi:10.1186/1479-5868-7-82

[6] Gouvali, M.K. and Boudolos, K. (2006) Match between school furniture dimensions and children's anthropometry. Applied Ergonomics, 37, 765-773. doi:10.1016/j.apergo.2005.11.009

[7] Harreby, M., Neergaard, K., Hesselsoe, G. and Kjer, J. (1995) Are radiologic changes in the thoracic and lumbar spine of adolescents risk-factors for low-back pain in adults: A 25-year prospective cohort study of 140 schoolchildren. Spine, 20, 2298-2302. doi:10.1097/00007632-199511000-00007

[8] Nygaard, B., Jessen, T., Larsen, E., Storr-Paulsen, A., Lindahl, A., Fisker, I., et al. (1999) Risk factors for low back pain in a cohort of 1389 Danish school children: An epidemiologic study. European Spine Journal, 8, 444-450. doi:10.1007/s005860050203

[9] Adams, M., Mannion, A. and Dolan, P. (1999) Personal risk factors for first-time low back pain. Spine, 24, 24972505. doi:10.1097/00007632-199912010-00012

[10] Salminen, J.J., Erkintalo, M.O., Pentti, J., Oksanen, A. and Kormano, M.J. (1999) Recurrent low back pain and early disc degeneration in the young: Significance of 
early disc degeneration. Spine, 24, 1316-1321. doi:10.1097/00007632-199907010-00008

[11] Geldof, E., De Clerq, D., De Bourdeaudhuij, I. and Cardon, G. (2007) Classroom postures of 8-12-year-old children. Ergonomics, 50, 1571-1581. doi:10.1080/00140130701587251

[12] Damkot, D.K., Pope, M.H., Lord, J. and Frymoyer, J.W. (1984) The relationship between work history, work environment, and low-back pain in men. Spine, 9, 395-399. doi:10.1097/00007632-198405000-00012

[13] Levine, J., Schleusner, S. and Jensen, M. (2000) Energy expenditure of nonexercise activity. The American Journal of Clinical Nutrition, 72, 1451-1454.

[14] Beers, E.A., Roemmich, J.N., Epstein, L.H. and Horvath, P.J. (2008) Increasing passive energy expenditure during clerical work. European Journal of Applied Physiology, 103, 353-360. doi:10.1007/s00421-008-0713-y

[15] Mancuso, A.R. (2010) The ability of the Sensewear armband to assess a change in energy expenditure in children while sitting and standing [Master of Science of Public Health]. School of Rural Public Health of the Texas A \& M University System Health Science Center.

[16] Benden, M.E., Wendel, M.L., Jeffrey, C.E., Zhao, H., Morales, M.L. (2012) Within-subjects analysis of the effects of a stand-biased classroom intervention on energy expenditure. Journal of Exercise Physiology, 15, 9-19.

[17] Franks P. (2010) Diabetes family history: A metabolic storm you should not sit out. Diabetes, 59, 2732-2734. doi:10.2337/db10-0768

[18] Katzmarzyk, P. (2010) Physical activity, sedentary behavior, and health: Paradigm paralysis or paradigm shift? Diabetes, 59, 2717-2725.doi:10.2337/db10-0822

[19] Levine, J. (2010) Health-chair reform: Your chair: Comfortable but deadly. Diabetes, 11, 2715-2716. doi:10.2337/db10-1042
[20] Cardon, G., De Clerq, D., De Bourdeaudhuij, I. and Breithecker, D. (2004) Sitting habits in elementary schoolchildren: A traditional versus a "moving school”. Patient Education and Counseling, 54, 133-142. doi:10.1016/S0738-3991(03)00215-5

[21] Fransson-Hall, C., Gloria, R., Kilbom, A., Winkel, J., Karlqvist, L. and Wiktorin, C. (1995) A portable ergonomic observation method (PEO) for computerized on-line recording of postures and manual handling. Applied Ergonomics, 26, 93. doi:10.1016/0003-6870(95)00003-U

[22] Murphy, S., Buckle, P., Stubbs, D. (2002) The use of the portable ergonomic observation method (PEO) to monitor the sitting posture of school children in the classroom. Applied Ergonomics, 33, 365-370. doi:10.1016/S0003-6870(02)00003-0

[23] Benden, M., Blake, J., Wendel, M., Huber, J. (2011) The impact of stand-biased desks in classrooms on calorie expenditure in children. American Journal of Public Health, 101, 1433-1436. doi:10.2105/AJPH.2010.300072

[24] Wingrat, J. and Exner, C. (2005) The impact of school furniture on fourth grade children's on-task and sitting behavior in the classroom: A pilot study. Work, 25, 263272.

[25] Koskelo, R., Vuorikari, K., Hanninen, O. (2007) Sitting and standing postures are corrected by adjustable furniture with lowered muscle tension in high-school students. Ergonomics, 50, 1643-1656. doi:10.1080/00140130701587236

[26] Wang, Y.C., Orleans, C.T. and Gortmaker, S.L. (2012) Reaching the healthy people goals for reducing childhood obesity: Closing the energy gap. American Journal of Preventive Medicine, 42, 437-444. doi:10.1016/j.amepre.2012.01.018 